\title{
CRIMINAL LAW REVISION IN CANADA
}

\author{
ALAN W. MEWETT*
}

The Criminal Law in Canada is clearly in need of revision but the machinery to do so is inadequate. Reform has only been haphazard and made without the assistance of modern criminological studies. The author proposes the establishment of a permanent Criminal Law Revision Committee to solve these problems. He sets out what its constitution and functions should be but emphasizes that it would compliment rather than replace our system of parliamentary responsibility.

In 1958, the Society of Public Teachers of Law (The English equivalent of the Association of Canadian Law Teachers) presented a memorandum to the then Lord Chancellor urging the establishment of a permanent criminal law revision committee. The memorandum read, in part:'

It is true that some proposals for reform raise such wide issues of social policy that they can properly be considered only by a body having broadly based membership, such as a Royal Commission. There are, nevertheless, many others which could best be entrusted to a committee composed of judges and practising and academic lawyers. ... .

We are concerned only to make out a case for the establishment of some permanent machinery. . . . In carrying out its work, such a committee as we envisage would no doubt be greatly assisted by various Dominion and Colonial Codes, and the work of the American Law Institute, which is currently preparing a Model Penal Code containing some interesting solutions to some of the vexed problems of the criminal law. It is many years since the Criminal Law of the United Kingdom has been subjected to a comprehensive review. In our view the time has arrived when such a review cannot long be postponed.

The memorandum was received by the Lord Chancellor and in $\mathbf{1 9 5 9}$ the British Government established a standing Criminal Law Revision Committee to which the Home Secretary refers such criminal law problems as he considers desirable. The Committee, after study, reports back to the Home Secretary, whose responsibility it is to take any steps he then considers appropriate. Some idea of the work of the Committee can be seen from the list of its Reports:

Indecency with Children (1959)

Suicide (1960)

Insanity (1963)

Order of Closing Speeches (1963)

Jurors (1964)

Purjury and the Attendance of Witnesses (1964)

Felonies and Misdemeanours (1965)

Theft (1966)

Evidence (1966).

The reform of the criminal law is, as we are seeing in Canada, a complex matter, as, indeed, is all law reform. Legislation is a political exercise and the ultimate responsibility for enacting statutory changes must rest with members of Parliament, and more specifically, with the government of the day. Under our system of government it cannot be any other way. The organization of government departments is such that they contain within them, as permanent civil servants, "experts" in the field of their responsibility.

It is difficult to talk about the "normal" process of reform of the

- LL.B. (Birmingham) B.C.L.. (Oxon.) LL.M., S.J.D. (Michigan), Professor of Law, University of Toronto.

1 (1958). 4 J. Soc. Pub. Teach. Law 237-32. 
criminal law since it has hitherto largely been a somewhat haphazard undertaking, but, as is the case again with all legislation, a reform starts as an idea in someone's mind. The "someone" may be a lawyer, a politician, a newspaper editor or the man in the street. It may be prompted by some piece of social injustice, real or imaginary, that he has observed; it may be the result of intellectual exercise; it may be the result of a personal belief or idiosyncracy. For the idea to be translated into action, it is necessary to persuade the appropriate Minister of the desirability of reform. The first step, therefore, is to communicate the idea to the Minister and this may be done merely by writing to him (though the efficacy of this method depends to a large extent on the status of the person writing and the interest and responsibility of the Minister). An intelligent and responsible newspaper campaign may make it irresistable for the Minister to take some steps. A private member of Parliament may raise the matter in the House and thus force the Minister at least to consider it. If no method is successful, the idea becomes buried in the graveyard of lost causes.

One does not normally expect the Minister of Justice to be himself omniscient, and he will take advice. In the usual course of things he will consult his "expert" civil servants. Unfortunately no expert can be an expert in all things, and how expert the experts are in the matter of criminal law reform depends upon the constitution of the department at any given time. The department has a criminal justice division, but, of course, it has responsibility for much more than analysing proposed legislation. Indeed, it is not unfair to state that their expertise consists more in the practice and enforcement of all aspects of criminal law than in its reform.

The Minister may, therefore, from time to time, refer proposed legislation to bodies who might likely be able to give him the benefit of its scrutiny from the point of view of the validity of the legislation, its impact and practical effect. One important body is the Conference of the Commissioners on Uniformity of Legislation composed of The Provincial Deputy Attorneys General, The Deputy Minister of Justice, and such others as are appointed by the Lieutenant-Governors or Governor-General as the occasion arises. While this body is not solely or even primarily concerned with criminal matters, it does exercise this important consultative function. It is also not uncommon for the Minister to ask for the views of organizations such as the Canadian Bar Association or the Canadian Corrections Association or individuals who, he has reason to believe, may be able to assist.

Either at that stage, or before, the Minister will have discussed the proposals in Cabinet and if the Cabinet agrees on the desirability of the legislation, the amending bill will be introduced. Its passage through Parliament is similar to that of any other government proposal, the Commons Committee being the Justice Committee and that of the Senate being the Banking and Commerce Committee. Occasionally it happens that even where the government does not see fit to propose the legislation, a private member may introduce a private member's Bill, and while this does not stand much chance of passage, a number of such amendments have been passed in this way, either with tacit government approval or at least without government opposition. 
An alternative, an important route to reform, is via the independent action of either the appropriate Commons Committee or the appropriate Senate Committee, independent in the sense that either of these Committees might hold hearings as to the desirability of reform before a Bill has been sent to them in the usual course of its passage through Parliament. The Committee will then report and, as a result, the proposed legislation drafted.

It is important not to underestimate the value of these "normal" methods of proceeding. Their advantages are many, if one admits that the reform of the Criminal Law must be legalistic, in the sense of having to be properly drafted, interpreted and put into effect, it must be social in the sense that all legislation affects society's actions and reactions and also that it must be political in the sense that popular votes are involved and political parties, and private members do have some, usually selfish, but occasionally altruistic, interest in remaining elected. Legislation conducted in this manner comes under the scrutiny of professional lawyers, experienced politicians and duly elected representatives of the community.

Nevertheless the drawbacks are considerable. In the first place, proposals for reform are haphazard. The initiative is, as it were, undirected, and, indeed, may be misdirected. A private individual or a newspaper editor may imagine wrongs and injustices that do not exist; members of parliament may be less rational than emotional in attacking present laws and in seeing imaginary defects; civil service lawyers, while they may be experts in one area, are not necessarily experts in law enforcement and criminal procedure; and, lastly, consultative bodies that may be asked for advice tend to be biased and to see things from only one point of view.

Most important of all, however, is that the machinery is totally inadequate to deal with the increasingly complex issues inherent in all criminal legislation. Criminology is a comparatively new science but it is becoming totally absurd to attempt to legislate criminal law without some regard for the lessons not so much that criminology has taught us as that criminology is in the process of teaching us. Criminology is an unfortunately vague word and we all have our own ideas of what it means. In this context, I use it in the widest sense to embrace the concept of the criminal law in action and its impact on society. Perhaps more than anything else this requires the gathering and digesting of a great deal of factual information and an analysis of its significanceinformation, for example, about the rates of crime, its causes, its prevalence, about the effect of sentencing procedures and recidivism. It also requires an understanding of the phenomenon of criminal law, what its purpose is, how best that purpose can be achieved and so on.

This sort of work is being done, notably at the Centre of Criminology in Toronto, at the Institute of Criminology in Montreal and at the Department of Criminology in the University of Ottawa. One is, of course, perfectly free to disagree with any conclusions that may be drawn from the information retrieved, but it is essential that that information be available.

In the Nineteenth Century, criminology was in its infancy and, indeed in the common law world had scarcely made an appearance. The crim- 
inal law reforms of that period-and there were many very significant pieces of criminal legislation-proceeded without the benefit of such a study. Criminal law was regarded largely as paternalistic in nature as emanating from the innate good sense of the judges and the legislature as to what was the best method of controlling what they themselves considered to be dangerous activities. Increasingly, it became apparent that the justness of the criminal law depends not upon the intuitive hunches of the legislature but upon what its objectives are and how those objectives are going to be achieved.

From time to time in Canada, it has been recognized that certain criminal law matters cannot be the subject of criminal legislation without considerably more study than is possible in the ordinary course of proceedings. In such cases there are appointed either Departmental Committees (responsible and reporting to the Minister who appoints them) of Royal Commissions (appointed by and reporting in effect to Parliament). There have not been too many of these and it is interesting to list them; in 1956, the Report of the Committee appointed to inquire into the Principles and Procedures followed in the Remission Service of the Department of Justice of Canada (more commonly known as the Fauteux Report); in 1965 the Report of the Committee on Juvenile Delinquency in Canada; and in $\mathbf{1 9 6 6}$ the Report of the Special Committee on Hate Propaganda in Canada. The Royal Commissions have been, The Penal System (1938), Espionage (1946), Insanity as a Defence (1955) and Criminal Sexual Psychopaths (1958). In addition, of course, there was the Royal Commission on the Revision of the Criminal Code of 1953, but its terms of reference were limited to largely a tidying-up operation.

Presumably all these represent subject matters requiring wider or deeper study than could be given by the departmental civil servants, the standing committees and members of Parliament. Ministers and governments from time to time have recognized the inadequacy of "normal" procedures-at least in areas tending toward the correctional side of criminal law. To what extent the recommendations contained in Committee and Commission reports have been implemented is, of course, another matter. Neither a Committee to a Minister nor a Commission reporting to Parliament need be concerned with the political aspects of any given problem-political, that is, in the sense of winning or losing votes. Nor, perhaps, are they too worried about the problem of raising sufficient funds to pay for any proposed programmes, though doubtless, this is considered to some extent. The government in power must, understandably, worry about both.

Criminal legislation can never, therefore, be divorced from the political arena and it would be most undesirable if it were. It is, however, interesting to compare the proceedings in Parliament on the legislation resulting from the Fauteux Committee Report with those on the legislation, for example, concerning the introduction of capital and non-capital murder.

The Fauteux Committee's recommendations have not, by any means, been implemented in full and, indeed, some of its more interesting and forward-looking proposals seem to have been ignored or forgotten, but its main recommendation, of course, concerned the establishment of a 
National Parole Board in place of the former Remission Service. It is quite clear from the Hansard report of the debates of 1958 that all Members who spoke had read the Report, and had fully understood its implications. The questions and suggestions were to the point. In other words, the debates were informed, rational and constructive.

In contrast, one can only describe the debates over the Criminal Code (Capital Murder) Amendment Act of 1960-61 as the complete opposite. The inarticulate premise was the desire of some Members to abolish capital punishment, and, if that was not possible, to reduce its incidence as much as possible. Others were not abolitionists, but genuinely believed that the death penalty should be reserved for the most serious form of murder. Opposition to the Bill came from those believing this was the thin edge of the wedge to abolish hanging (with some justification), from those who did not think it went far enough, and from those who thought the distinction between capital and non-capital murder was misconceived. In spite of the fundamental importance of the subjectmatter, little thought was given to the practical problem of how the courts were going to work out the definitions, of how the amendment would affect convictions, the probable proportion of capital/non-capital murder charges, the philosophical justification for the distinction and so on. Largely, the debates were centred on emotionalism and the subjective reactions of members to the proposals.

Unfortunately, The National Parole Bill type of proceedings is not, in the field of criminal legislation, the rule, but rather the exception, though in other areas within the federal competence, no government would proceed without detailed and thorough study of the problem and the proposed legislation by competent experts. If this is because of a feeling that expertise in criminal law is a matter of hunch, whereas in fields such as taxation, constitutional law or housing it is one of research and study, it is about time that the belief was shattered.

Law revision and law reform bodies of one sort or another are not novel and daring. They have existed in England, Scotland, Australia, New Zealand and a dozen or so states of the United States of America for a number of years. In Canada, the Ontario Law Reform Commission has been responsible for a great deal of improving legislation in a number of areas within the provincial jurisdiction, and is still continuing its work under the chairmanship of H. Allan Leal, Q.C., with the very acitve support and interest of the Attorney-General and the Ontario Government which provides it with adequate funds. Alberta has, somewhat more recently provided for a similar body under the direction of W. F. Bowker, Q.C., and there is every reason to suppose that it, too, will be active in law reform and have the full support of the government.

It is difficult to generalize about the procedures and operations of a typical civil law reform commission, but it is unnecessary to deal with them all specifically. It will have referred to it matters that have come to the attention of the appropriate Minister and that he considers to be in need of examination and research, or, alternatively, the Commission will outline areas that it considers in need of revision. Usually, most Commissions operate under both techniques. Once the area of study has been defined, either by reference or by its own motion, the research commences in the most appropriate way. Clearly this will vary from 
topic to topic. Field studies and fact-finding task forces might be appropriate. In most cases, comparative studies will be undertaken to see what is being done in other jurisdictions. Public hearings may also be held.

In due course, the Commission will be in possession of submissions, working papers, statistical information and the like and will then begin its task of digesting, analysing and sorting. After this, it is then in the position of being able to report to the Minister concerned. Practice varies as to whether this Report is for the private use of the Minister or whether it is for general publication, but most often the Report is published, and, in my opinion, this is the preferred practice. While it may be that a Minister has referred a matter for a report, the Commission or Committee constitutes a public body, supported by public funds and the public has the right to know the contents of its reports. Furthermore, the less secrecy there is, the more there is an onus on the Minister to justify his subsequent actions.

What the Minister does with the Report is his responsibility. In no jurisdiction, is there any suggestion that the establishment of a law reform committee or commission in any way deprives the Minister of both the right and the duty to act as a responsible member of parliament. He may introduce legislation implementing the proposals entirely; he may introduce legislation only partially implementing it; or, indeed, he may shelve it entirely. But the interesting, and important result is that, whatever course he adopts, it must be justified. Where a Report is implemented, it will contain its own justification. It is, of course, open to attack from Members of Parliament and the public and it will be attacked if they feel that it is misconceived or does not go far enough.

If it is only partially implemented or not implemented at all, the Minister will have to give his reasons. Hansard is liberally sprinkled with questions as to why various Reports have not been acted upon or when the Minister is going to introduce legislation to implement them. And this is how it should be. What does invariably appear is that all parties are well-informed and, as a result, the discussions and debates reflect a very genuine and rational understanding of the problems.

I should have thought that the case for a permanent criminal law reform committee in Canada was so clear that little argument could be necessary. Unfortunately, successive Ministers of Justice have ignored repeated proposals for its establishment and perhaps the case is less clear than I think.

In the first place, the criminal law is in need of revision in this country. There has been no systematic revision since 1892 when the Code was first enacted and yet clearly, there is need to consider whether the values and premises of the Nineteenth Century are still valid for the second half of the Twentieth. Most of the existing criminal law has been legislated without the benefit of criminological and sociological studies and it may well be that we are working on totally misconceived hypotheses.

Second, what amendments there have been, have been haphazard and inconsistent. On the one hand, the proposals to legalize, to a limited extent, abortion have come in for more public discussion and debate than practically any other measure in recent years. On the other hand, the inclusion of the relatively minor offence of indecent assault in the list 
of "constructive murder" offences in Section 202 of the Code was virtually an afterthought following a somewhat sordid episode in Western Canada, while the phraseology of Section $202(d)$ was the result of the Senate's insistence on making causing death while having a gun in one's possession under certain conditions murder, quite regardless of any mens rea as the Commons wished.

Third, isolated tinkering is probably worse than useless. One cannot deny the value of the Reports of Commissions and Committees that have already been produced. All of them, however, have had narrow, specific terms of reference as such bodies must have. However valuable as isolated studies they may be, none of them has had the breadth and coverage which is required. One exception to this, it is to be hoped, is the Canadian Committee on Corrections under the Chairmanship of Mr. Justice Ouimet, but specifically excluded from the terms of reference was any consideration of the substantive criminal law of Canada. While, therefore, the Report of the Committee will doubtless range over a wide area of the correctional aspect of criminal law, it will be unable to deal, at least in any detail, with substantive criminal law reform.

The problem is, of course, that Canada remains one of the very few countries of the world with a Criminal Code rather than a Penal Code. There is, I would suggest, a fundamental fallacy in attempting to compartmentalize the criminal law into discrete areas of substantive law, procedure, and corrections. To attempt reform in one area without considering its repercussions in the other leads, if not to a backward step, at least to a wasted effort. An ad hoc Committee or Commission charged with inquiring into a specific area, may find its terms of reference too limited to permit a proper investigation. Furthermore, the pressure to work to a time limit may adversely affect its work.

Government use of the existing institutes, schools and departments of universities has, thus far, been disappointing. Financial assistance has been niggardly, more, I suspect, because of a complete lack of understanding of what worthwhile research entails than because of innate meanness. Where grants are made, there is a tendency to dictate not only what research is to be done but also how it is to be done, and while the body that provides the funds may be perfectly proper in asking for certain studies to be made, the researcher must be left free to research in the way in which he, as the expert, thinks will be most productive.

To me, the conclusion is inevitable that a permanent body must be established for the purpose of undertaking continuous studies for the revision and updating of the criminal law in its widest sense, and it becomes necessary to consider the constitution of such a body, its methods of operation, its financing, and its responsibility.

The constitution depends, to a large extent, on its methods of operation and what it is proposed to accomplish. As stated earlier, the criminal law does not, any longer at any rate, exist in a vacuum, isolated from "criminology", or the criminal law in action. For any body to undertake any meaningful revision of the criminal law, therefore, it either has to be composed not only of "legal" experts but also of "sociological" experts or, if it is composed only of legal experts, it must not and cannot act without adequate consultation with and ad- 
vice from specialists in other fields of criminology, where this is indicated by the area of revision.

It seems to me, however, that the primary functions of a criminal law revision committee are to delimit the area of study, analyse all relevant data which has been assembled either by it or for it, and report to the Minister a coherent proposal for legislation. It must be aware of the legal problems involved in solutions to sociological problems; it must consider practical aspects of interpretation, construction and application. To this end, it would appear preferable for the Committee itself to be composed of lawyers familiar with all aspects of the legal problems involved and I would suggest that this basically entails members of the judiciary, members of the practising bar, and academic lawyers, with, though I do not consider the matter of the gravest significance, a judge or ex-judge as the Chairman.

But such a Committee cannot be expected to possess all the expertise necessary for criminal law reform. There are some areas, undoubtedly, where it would be competent-for example, some procedural matters, "tidying-up" revisions and the like. In other fields, such as those affecting police powers, it may have to receive oral or written presentations. With the vast bulk of substantive criminal law, it would have to go further. It is absolutely essential that we cease attempting to reform the criminal law in our current blindfolded, groping manner. There can be no valid reform without statistical data and comparative studies to prove or refute premises upon which we work.

Dean Manning in his Introduction to Law in a Changing America, edited by Professor Hazard, wrote:

Until Professor Kalven's study, no one had ever really tried to lcarn what juries actually do and with what consequences. ... What really happens in juvenile courts? Who in fact receives what kinds of criminal penalties for what kinds of offenses? How is the behaviour of investors actually affected by different kinds of securities regulations? What have been the actual effects of the Miranda case? . . . The answers to all these questions, and a million more like them, is that we do not know, that we could find out, and that we are still not trying to find out. As a result, decision makers in our judicial, legislative and administrative institutions continue to follow rules, change rules, and make new rules in what is often virtually a factual vacuum.

Valid criminal law revision depends upon three relatively simple things. First, someone to know what questions to ask; second, someone to know how to answer these questions; and, third, someone to assimilate those answers into the right solutions.

A criminal law revision committee must be composed of people who know when they have to ask questions and of whom. For example, it strikes me as totally absurd to propose legislation enabling easier abortions without enquiring into such matters as the statistical size of the problem created by the present legislation; the number of unnecessary deaths caused; the effect of similar legislation in other countries; the probable social repercussions of the proposals and so on. What is the point of legislating on homosexual activities when we do not know much-if anything-about the phenomenon, about how many people it affects, about what has happened in England or Illinois as a result of their changes. Thus, it is useless to have a committee composed of persons being rewarded for past services: they must be persons who are aware of what the problems are and what information is needed before changes can be contemplated. 
I categorically deny that Canada lacks the resources for carrying out the required studies. Not only do we have schools and institutes of criminology, but we also have good schools of social work, departments of sociology, psychiatric centres, hospitals, and law faculties, all staffed by able and competent individuals, who would be anxious, if asked, to contribute to such a cause.

However, sad to relate, it does cost money-money for research workers, for equipment, for computers, for typists-but how can it possibly be denied that the federal government has the obligation to provide the necessary financial support? In any case, compared to the cost of crime, the cost of the administration of criminal justice and the cost of correctional and rehabilitative programmes, we are not talking in terms of astronomical amounts. Research workers, field workers, university personnel and the sort of people contemplated expect some remuneration but not lavish honoraria and extravagent expense accounts.

The responsibility of the Committee, in short, must be (i) to delimit areas of study, either on their own initiative or after reference (ii) to decide what sort of study is necessary, that is, whether it can be accomplished by themselves, whether it lends itself to hearings or whether it requires reasearch (iii) to choose the appropriate research agency and request that the study be made, with, of course, the necessary financial support and (iv) to receive and analyse the results and report to the Minister.

From that moment on, it is right and proper that the matter becomes a "political" issue-not, one would hope in the petty party sense, but in the sense of it being the responsibility of the Minister, hence Cabinet, and hence Parliament to decide upon the appropriateness of legislation.

Two final points should be made. The first is that criminal law reform is a continuing process just as the criminal law itself must keep pace with changes in society. Many items already need reform, but even if reformed according to present day standards, there must be a constant periodic review to ensure that the gap between what the law is and what the law should be does not become too great-certainly, one hopes, never greater than it is now.

The second point is that there will always be a need for the occasional Royal Commission or Special Committee. Certain areas involving, particularly, public moral or cultural concern may be better suited to the public enquiry type of process. My own personal view is that a Royal Commisison on Obscene Literature, or Narcotic Drug Offences for example, would serve a more useful purpose than any attempt at reform by a law revision committee. However, this is a judgment which the Minister concerned must exercise.

Let me conclude by repeating what I have previously said:

The sad conclusion is that the criminal law has not progressed in one hundred years nor can it progress beyond a slight reshuffling within assumed boundaries so long as those boundaries are accepted as absolutes. There have, of course, been changes that, within the structure, have been beneficial and to that extent advances have been made. But it is not a cause for congratulation that Sir James Stephen would be quite at home with the Criminal Code of 1967." 